\title{
Pelatihan Pengelolaan Kelas Daring yang Kreatif dan Inovatif melalui Google Classroom
}

\author{
Henry Aditia Rigianti ${ }^{1}$, Puguh Ardianto Iskandar ${ }^{2}$, Ari Wibowo ${ }^{3}$, \\ Budiharti $^{4}$ \\ ${ }^{1}$ Elementary School Teacher Education, The Faculty of Teacher Training and Education, \\ Universitas PGRI Yogyakarta, Indonesia \\ ${ }^{2}$ Elementary School Teacher Education, The Faculty of Teacher Training and Education, \\ Universitas PGRI Yogyakarta, Indonesia \\ ${ }^{3}$ Elementary School Teacher Education, The Faculty of Teacher Training and Education, \\ Universitas PGRI Yogyakarta, Indonesia \\ ${ }^{4}$ Elementary School Teacher Education, The Faculty of Teacher Training and Education, \\ Universitas PGRI Yogyakarta, Indonesia
}

Corresponding email: henry@upy.ac.id

\begin{abstract}
The quality of learning during the pandemic is not optimal, it can be seen that learning has not fully implemented classroom management through online media. Therefore, teachers are expected to be able to implement creative and innovative learning through Google Classroom. With the phenomenon of online learning, teachers and devotees work together to conduct face-to-face training by observing strict health protocols. Classroom management training on the use of google classroom was conducted at SD Muhammadiyah Ambarketawang 1, Yogyakarta. As many as 22 people, both from teachers and servants, conducted training in May 2021. The techniques used in this action, among others, were providing information about the use of google classroom, creating classes, uploading materials, making attendance, and evaluating student assignments. From the survey results, it is known that there are $85 \%$ of educators who use the whatsapp application as an online learning medium and $15 \%$ of teachers use the google classroom application. The results of the training showed that $20 \%$ of teachers said it was easy, $65 \%$ moderate and $15 \%$ difficult.
\end{abstract}

Keywords: class management; google classroom; online. 


\begin{abstract}
ABSTRAK
Kualitas pembelajaran masa pandemi belum optimal, hal ini dapat dilihat pembelajaran belum sepenuhnya mengimplementasikan pengelolaan kelas melalui media daring. Maka dari itu, guru diharapkan mampu mengimplementasikan pembelajaran kreatif dan inovatif melalui google classroom. Adanya fenomena pembelajaran daring tersebut, guru Bersama pengabdi beerjasama melakukan pelatihan secara tatap muka dengan memerhatikan protokol kesehatan secara ketat. Pelatihan pengelolaan kelas pada pemanfaatan google classroom dilalkukan di SD Muhammadiyah Ambarketawang 1, Yogyakarta. Adapun sebanyak 22 orang, baik dari guru maupun pengabdi melakuan pelatihan pada bulan Mei 2021. Teknik-teknik yang digunakan dalam tindakan ini, antara lain, memberikan informasi tentang pemanfaatan google classroom, membuat kelas, mengunggah materi, membuat presensi, dan evaluasi tugas siswa. Dari hasil survei diketahui bahwa terdapat $85 \%$ pendidik memanfaatkan aplikasi whatsapp sebagai media pembelajaran online dan $15 \%$ pengajar memanfaatkan aplikasi google classroom. Hasil pelatihan menunjukkan bahwa $23.5 \%$ guru mengatakan mudah, $64.7 \%$ sedang dan $11.8 \%$ susah.
\end{abstract}

Kata kunci: pengelolaan kelas; google classroom; daring.

\title{
PENDAHULUAN
}

Pandemi Covid 2019 (Coronavirus) yang telah mencapai lebih dari 200 negara di dunia ini, menyajikan kesulitan baru di bidang sekolah, terutama untuk pelatihan penting yang harus dengan cepat mengharapkan (Arora, 2020; Sneling, 2020). Untuk mencegah penyebaran Coronavirus, yang memberikan daya tarik dalam pembelajaran haruslah membuat pengelolaan kelas melalui pembelajaran jarak jauh melalui jaringan internet. Hal ini bisa dikatakan dengan implementasi pembelajaran online untuk semua aktivitas pembelajaran di sekolah. 
Penyesuaian pembelajaran dari luring ke online tentunya harus melalui beberapa tahapan yang tidak dapat diabaikan oleh pendidik (Collie et al., 2011). Sebagai seseorang pendidik tentunya diharapkan memiliki keterampilan yang dapat dibuktikan di bidang pengajarannya, pendidik harus mampu memberikan materi secara jelas tanpa mengurangi semangat belajar siswa. Solusi pembelajaran selama pandemi bisa melalui pembelajaran daring melalui web dengan pengelolaan kelas yang kreatif dan inovatif.

Pembelajaran berbasis web adalah gerakan belajar yang menyatukan pendidik dan memberikan pengalaman baru untuk berkomunikasi melalui jaringan web (Kuntarto, 2017). Dalam pelaksanaan pembelajaran online, guru dapat menggunakan peralatan seperti perangkat komputer atau PC dan web sebagai metode untuk mendukung pembelajaran. Pemanfaatan web dan inovasi media interaktif dapat mengubah cara informasi yang disampaikan dan dapat menjadi pilihan berbeda dengan pembelajaran dilakukan di ruang belajar konvensional (Zhang et al, 2004).

Pernyataan kepala SD Muhammadiyah Ambarketawang 1, ditemukan selama pembelajaran, para pendidik mayoritas menggunakan aplikasi WhatsApp sebanyak $85 \%$ sebagai metode untuk belajar dan menyampaikan materi. Semua bahan dan tugas yang diberikan oleh guru kelas dikirim melalui whatsapp baik video, soal, maupun materi. Hal ini tentunya mudah dilakukan dalam pembelajaran, namun pendidik merasa ada kekurangan dalam melakukan pembelajaran. Diantaranya terjadi keingungan siswa saat diskusi, dikarenakan tertumpuknya chat. Membutuhkan penyimpanan besar dalam handphone dan kadang-kadang pesan terhapus tidak bisa terlihat lagi. Sedangkan pernyataan guru lainnya mengalami kesulitan evaluasi, dikarenakan harus mengunduh satu persatu bahkan ada yang terlewat dalam memberikan nilai kepada siswa. Pendidik harus memilih tugas, memindahkan catatan, dan memeriksa apakah nama pengirim dan nama dokumen cocok.

Fenomena diatas dapat dilihat pendidik sebagai dasar perubahan proses pembelajaran dengan memperhatikan asas efektivitas dan kemudahan. Inovasi pembelajaran juga dapat diberikan agar dapat menemukan jawaban untuk setiap 
masalah yang mereka hadapi. Setiap hambatan atau masalah yang muncul dalam interaksi pembelajaran harus mampu menghasilkan pengelolaan kelas dan hasil belajar siswa yang memenuhi kriteria ketuntasan.

Kehadiran media pembelajaran baru adalah metode lain untuk memberikan pengalaman yang berbeda dalam proses transmisi materi dan pengalaman belajar siswa menggunakan teknologi komputer. Seperti yang ditunjukkan oleh McQuil (2006: 26) Ada dua hal yang terkandung dalam inovasi media, untuk situasi ini, web dapat mengubah peserta didik memiliki perspektif yang berbeda dan memberikan keterampilan meggunakan media internet ataupun tenologi lainnya. Media web ini juga dapat mengubah cara individu menyelesaikan masalah, khususnya dalam dunia pendidikan.

Perlunya inovasi ditandai adanya beberapa media baru yang mewajibkan guru harus beralih ke media yang lebih baik dan lebih tepat guna, terutama dalam implementasi dan evaluasi pembelajaran. Kehadiran google classroom dipandang sebagai alternatif lain untuk mendorong penyampaian informasi logis dengan tepat. Dengan bantuan data tanpa batas, pengguna google classroom dapat mengakses sesuai kebutuhan tanpa harus membatasi jumlah penyimapanan. Inovasi lain berdasarkan platform google classroom dapat menjadi pengganti media sederhana whatsapp dengan tujuan mengubah siklus konvensional sehingga pembelajaran berjalan lebih baik dan mampu memberikan pengalaman baru dengan literasi teknologi siswa.

Di bidang pengajaran, beberapa strategi pembelajaran web telah berfokus pada pembelajaran internet atau e-learning. Affects of the Investigation (Sabran dan Sabara, 2014: 122) Ekspresikan bahwa memanfaatkan media baru adalah penggunaan serbaguna karena dapat menyampaikan perkembangan pengaturan dalam teknik pengajaran dan pembelajaran.

Pemanfaatan google classroom sebagai proses pembelajaran membantu guru untuk melaksanakkan tugas dan menghubungkannya dengan penyimpanan atau data based di Google Drive. Kemampuan beradaptasi waktu dan lokasi juga menjadikan google classroom ukuran pembelajaran yang disukai. Serta membuat 
pendidik lebih mudah dan gratis, mereka juga melakukan pertemuan melalui percakapan di kelas secara umum dan pribadi dalam hal apa pun. Kehadiran google classroom sebagai salah satu media pembelajaran populer dan membuat pengalaman lain untuk diimplementasikan secara baik.

Pernyataan Anugrah (2020), pandemi Coronavirus mungkin merupakan titik awal untuk mengubah penemuan penting terhadap kebaharuan pembelajaran, kemajuan dalam ilmu pengetahuan dan inovasi teknologi pembelajaran. Oleh karena itu, melalui pelatihan dalam pengabdian masyarakat di SD Muhammadiyah Ambarketawang 1 dapat meningkatkan kualitas pembelajaran guru melalui platform google classroom. Hal lain juga dalam pelatihan mampu memberikan dan menvohtohkan pengelolaan kelas yang kreatif dan inovatif dalam pembelajaran online.

\section{METODOLOGI PENELITIAN}

Kegiatan pengabdian masyarakat ini dilaksanaan di salah satu ruang kelas SD Muhammadiyah Ambarketawang 1, Yogyakarta, yang terletak di desa Bodeh, RT 4 RW 24, kelurahan Ambarketawang, kecamatan Gamping, kabupaten Sleman, Daerah Istimewa Yogyakarta 55294. Pengabdian dilaksanakan pada hari Kamis, 20 Mei 2021. Anggota kegiatan pengabdian ini adalah guru SD Muhammadiyah Ambarketawang 1, Yogyakarta dan pengabdi sebanyak 22 individu. Metode yang digunakan dalam pelatihan melalui penyampaian materi secara tatap muka dilanjutkan latihan bersama dengan membuat kelas melalui google classroom, memberikan cara pembuatan presensi melalui google form, megunggah materi baik berupa video, audio, maupun dokumen, dan yang paling penting evaluasi setiap siswa.

\section{HASIL DAN PEMBAHASAN}

Kegiatan PKM ini dilakukan melalui tatap muka dengan protocol kesehatan yang ketat. Teknik yang digunakan selama persiapan adalah pelatihan, diskusi, tanya jawab, dan strategi tugas. Pengabdi memperhatikan pelatihan yang diberikan dengan memanfaatkan google classroom. Ini dengan tujuan bahwa para guru dapat memahami ide-ide, juga siap untuk memahami metode untuk 
memanfaatkan google classroom untuk meningkatkan interaksi pembelajaran. Dari hasil survei diketahui bahwa terdapat $85 \%$ pendidik memanfaatkan aplikasi whatsapp sebagai media pembelajaran online dan $15 \%$ pengajar memanfaatkan aplikasi google classroom. Berdasaran hasil pelatihan pemanfaatan google classroom melalui angket dapat dilihat pada tabel 1.

Tabel 1. Hasil jawaban responden terhadap pelatihan

\begin{tabular}{clcc}
\hline No & Kategori & Jumlah responden menjawab & Persentase \\
\hline 1 & Mudah & 4 & 23.5 \\
\hline 2 & Sedang & 11 & 64.7 \\
\hline 3 & Susah & 2 & 11.8 \\
\hline
\end{tabular}

Berdasarkan hasil pelatihan pengelolaan kelas menggunakan google classroom, menunjukkan bahwa sebanyak 4 guru atau sebesar $23.5 \%$ mengatakan mudah, sebanyak 11 guru atau sebesar $64.7 \%$ mengatakan sedang dan sebanyak 2 guru atau sebesar $11.8 \%$ mengatakan susah. Dapat disimpulkan bahwa guru mendapatkan pengalaman baru yang mana dapat menjadikan pembelajaran online menjadi menarik dengan menggunaan google classroom.

Kegiatan PKM ini dimulai dengan sambutan dari kepala sekolah, ketua pengabdian masyarakat, dan Dekan FKIP, Universitas PGRI Yogyakarta. Selain itu, pelatihan diawali dengan memberikan dan menyiapkan materi google classroom untuk meningkatkan interaksi pembelajaran di SD Muhammadiyah Ambarketawang 1, Yogyakarta. Adapun pemateri untuk pelatihan PKM adalah Puguh Ardianto Iskandar, M.Pd. Dokumentasi dari pembukaan, dan pemaparan materi pelatihan dapat dilihat pada Gambar 1 dan Gambar 2

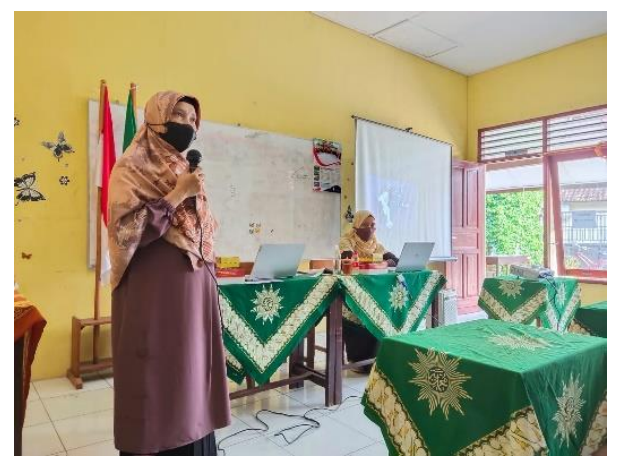

Gambar 1 Pembukaan pelatihan oleh tim pengabdian 


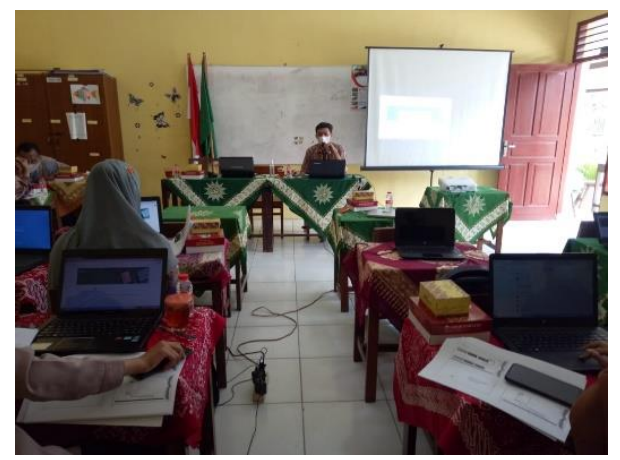

Gambar 2 Kegiatan pemaparan materi

Bahan persiapan meliputi: presentasi, metode untuk digunakan dalam pembelajaran, pengaturan pengembangan pembelajaran dengan google classroom, secara garis besar pertemuan dalam pelatihan ini melalui pemberian materi dilakukan dengan menayangkan contoh-contoh kelas kreatif dan inovatif melalui proyektor. Kemudian, pada saat itu ada diskusi dan praktik langsung dalam penggunaan google classroom untuk guru mengenai materi, penyampaian, dan evaluasi. Dokumentasi berbentuk praktik pendampingan dalam memanfaatkan google classroom dapat dilihat pada Gambar 3.

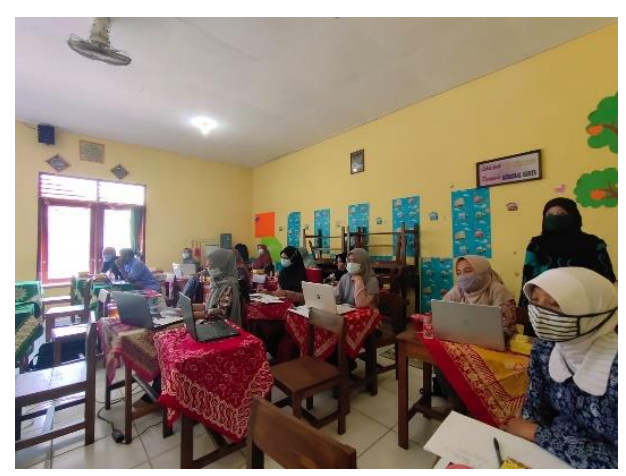

Gambar 3 Praktik pemanfaatan google classroom oleh guru

Dalam mempersiapkan latihan, guru melakukan embeddings melalui computer atau laptop dengan panduan pemateri di google classroom. Selain itu, guru mempelajari dan mencoba membuat ruang kelas di google classroom dan mengasumsikan bahwa manfaat google classroom dapat dilakukan dan dirasakan oleh siswa dan guru. Kegiatan guru dalam menggunakan google classroom dapat ditemukan pada Gambar 4. 


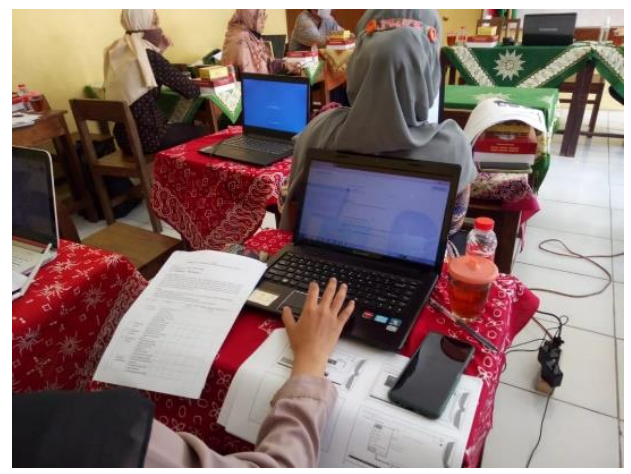

Gambar 4 Kegiatan Praktik Pelatihan

Kegiatan PKM ini dilakukan dengan penuh semangat dan mudah. Semangat peserta selama kegiatan dapat dilihat dari: 1) Anggota secara efektif memiliki minat pada setiap fase pelatihan dan praktik. Mereka juga aktif menanyakan jika mengalami masalah dalam menggunakan google classroom, 2) peserta juga aktif dalam membuat kelas berbasis web. Kegiatan ini adalah kerjasama antara Universitas PGRI Yogyakarta dan SD Muhammadiyah Ambarketawang 1, Yogyakarta. Mengingat persiapan yang telah selesai, guru mengungkap bahwa kegunaan google classroom membuatnya lebih mudah bagi mereka untuk berkomunikasi dengan waktu dan tempat tanpa dibatasi oleh keadaan. Hal ini sesuai dengan hasil pelatihan, bahwa google classroom memiliki beberapa manfaat, antara lain dalam administrasi penilaian, kecepatan evaluasi, dan tanpa kertas (paperless) (Hidayat dan Sudibyo, 2018). Pendidik juga dapat membuka ruang percakapan berupa diskusi dalam bentuk tulisan di web (Savitri, 2019).

\section{KESIMPULAN}

Pelatihan pengelolaan kelas daring di SD Muhammadiyah Ambarketawang 1, Yogyakarta diperoleh hasil sesuai ekspektasi. Sebanyak 4 guru sebesar $23.5 \%$ menyatakan mudah, 11 guru sebesar $64.7 \%$ menyatakan mudah, dan 2 guru sebesar $11.8 \%$ menyatakan susah. Hal ini dapat disimpulkan pelatihan berjalan dengan baik dan peserta pelatihan mampu menerima materi dengan baik. Kegiatan ini bermanfaat pada guru untuk meningkatkan pengelolaan kelas secara kreatif dan inovatif dalam proses belajar dan pembelajaran secara daring. 
Selanjutnya, tindakan ini menambah untuk memperluas informasi dan kapasitas pendidik dalam memanfaatkan google classroom sebagai media pembelajaran. Pemanfaatan google classroom diandalkan untuk membuat interaksi belajar menyenangkan, dengan tujuan yang secara tegas mempengaruhi hasil pembelajaran yang dipahami, serta meningkatkan kualitas kinerja guru.

\section{DAFTAR PUSTAKA}

Anugrah, D. (2020). Dinamika pembelajaran daring di tengah pandemi Covid-19. Berita Magelang.

Arora, A. K., \& \& Srinivasan, R. (2020). Impact of pandemic COVID-19 on the teaching-learning process: A study of higher education teachers. Prabadhan: Indian Journal of Management, 13 (4).

Collie, R. J., Shapka, J. D., \& Perry, N. E. (2011). Predicting teacher commitment: The impact of school climate and social-emotional learning. Psychology in the Schools, 48(10), 1034-1048.

Hidayat, W., \& Sudibyo, N. A. (2018). Implementasi pembelajaran interaktif elektronika dasar menggunakan adobe flash cs6 pada kelas semu dengan google classroom berbasis framework rad. Jurnal Sains Dan Edukasi Sains, $1(2)$.

Kuntarto, E. (2017). Keefektifan Model Pembelajaran Daring dalam Perkuliahan Bahasa Indonesia di Perguruan Tinggi. Indonesian Language Education and Literature, 3(1).

Mc Quail, Denis. (2006). Teori Komunikasi Massa Suatu Pengantar. Alih bahasa oleh Agus Dharma dan Aminudin Ram. Jakarta: Erlangga.

Sabran, \& Sabara, E. (2014). Keefektifan Google classroom sebagai media pembelajaran. Diseminasi Hasil Penelitian Melalui Optimalisasi Sinta Dan Hak Kekayaan Intelektual, 122-125.

Savitri, D. I. (2019). Penggunaan pembelajaran 4.0 berbantuan aplikasi google classroom dan google form dalam mata kuliah ilmu sosial budaya dasar. Jurnal Borneo Saintek, 2(1). 
Snelling, J., \& Fingal, D. (2020). 10 Strategies for Online Learning During a Coronavirus Outbreak. Deas, Content and Resources for Leading-Edge Educators.

Zhang, D., Zhao, J. L., Zhou, L., \& Nunamaker, J. F. (2004). Can e-learning replace classroom learning? Communications of the ACM. 